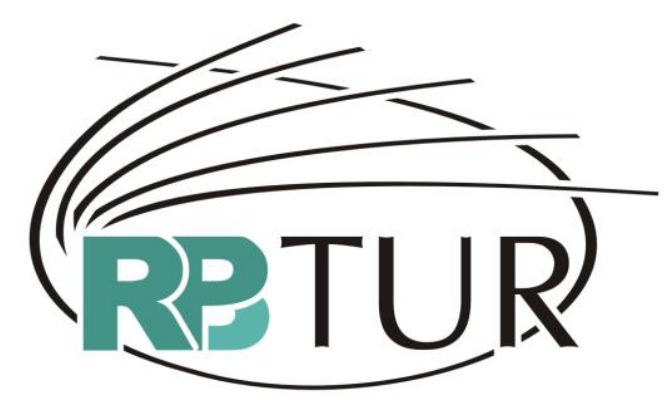

REVISTA BRASILEIRA DE PESQUISA EM TURISMO

\title{
O TERRITÓRIO EM MOVIMENTO NO ASSENTAMENTO RURAL SUL BONITO EM ITAQUIRAÍ/MS: A PRÁTICA TURÍSTICA NA PRAIA DA AMIZADE
}

\author{
MOVING TERRITORY IN THE RURAL SETTLEMENT SUL \\ BONITO IN ITAQUIRAÍ/MS: TOURISTIC USAGES AT PRAIA \\ DA AMIZADE
}

\section{EL TERRITORIO EN MOVIMIENTO EN EL ASENTAMIENTO RURAL SUL BONITO EN ITAQUIRAÍ/MS: LA PRÁCTICA TURÍSTICA EN LA PRAIA DA AMIZADE}

Daiane Alencar da Silva ${ }^{1}$ Edvaldo Cesar Moretti ${ }^{2}$

Resumo: $O$ objetivo da pesquisa foi compreender 0 território rural e seus movimentos a partir da inserção da atividade turística. A área de estudo é o assentamento rural Sul Bonito constituído de 421 famílias assentadas em 1996. Localizado no município de Itaquiraí, Mato Grosso do Sul, esse assentamento apresenta-se como um referencial relacionado a alternativas de produção. Este trabalho utilizou como metodologia a análise de dados obtidas através de trabalhos de campo, com entrevistas direcionadas a assentados que desenvolvem algum tipo de produção alternativa em relação às tradicionais práticas agropecuárias. A revisão de material bibliográfico relacionado ao objeto de estudo permitiu novos olhares e perspectivas de análise sobre as transformações ocorridas no território rural. Obtevese como resultado da pesquisa uma análise sobre a inserção do turismo no território rural e as conseqüências dessa prática produtiva no assentamento.

Palavras chave: Turismo. Território. Assentamento rural.

Abstract: The scope of the research is to understand rural areas and their changes since tourism upsurge. The study area is the rural settlement Sul Bonito comprising 421 families settled in 1996. Located in the municipality of Itaquiraí, Mato Grosso do

\footnotetext{
${ }^{1}$ Mestre em Geografia pela Universidade Federal da Grande Dourados. Docente contratada da Universidade Estadual do Mato Grosso do Sul. Email: daianeufgd@hotmail.com

2 Professor Doutor do Curso de Geografia da Faculdade de Ciências Humanas da Universidade Federal da Grande Dourados. Email: edvaldomoretti@ufgd.edu.br
} 
Sul, this settlement is presented as a reference on production alternatives. Methodology included field work and interviews with settlers who adopted ways of production alternative to traditional farming practices. Bibliographic research allowed new insights and perceptions about the changes occurring in the countryside. As a result, an analysis on tourism upsurge in rural areas and its consequences in production in the settlement was obtained.

Keywords: Tourism. Territory. Rural settlement.

Resumen: El objetivo del texto es comprender el territorio rural y sus cambios a partir de la inserción de la actividad turística. El área del estudio es el asentamiento rural Sul Bonito constituido de 421 familias asentadas en 1996. Localizado en la ciudad de Itaquiraí, Mato Grosso do Sul, que se presenta como referencial en relación a alternativas de producción. Este trabajo utilizó como metodología el análisis de los datos obtenido a través de trabajo de campo, con entrevistas dirigidas a los asentados que desarrollan algún tipo de producción alternativa en relación a las tradicionales prácticas agropecuarias. La revisión del material bibliográfico permitió nuevas miradas y perspectivas de análisis en las transformaciones ocurridas en el territorio agrícola. Como resultado de la investigación, se obtuvo un análisis sobre la inserción del turismo en el territorio rural y las consecuencias de esta práctica productiva en el asentamiento.

Palabras clave: Turismo. Territorio. Asentamiento rural.

\section{Introdução}

Em sua complexidade, analisando as formas que a atividade turística assume no assentamento rural e os significados para os assentados ao optarem pelo turismo como mais uma prática produtiva no campo, busca-se, neste texto, refletir sobre a produção do território como movimento da sociedade, abordando, especificamente, a inserção da prática social turística no assentamento rural Sul Bonito, localizado no município de Itaquiraí no Mato Grosso do Sul

A simplificação analítica esconde a importância da atividade turística no contexto das transformações verificadas localmente, mas articuladas à globalidade, e retira o turismo do contexto geral da reprodução capitalista.

A complexidade da atividade turística é pensada de acordo com a reflexão apresentada por Arlete Moisés Rodrigues (1997, p.83-84), onde o turismo é visto como uma prática social consumidora e produtora de espaço:

[...] esta atividade produz territórios, da mesma forma como todas as demais atividades do modo industrial de produzir mercadorias e na sua 
SILVA, Daiane Alencar da; MORETTI, Edvaldo Cesar. O território em movimento no assentamento rural Sul Bonito em Itaquiraí/MS: a prática turística na Praia da Amizade. Revista Brasileira de Pesquisa em Turismo.

v.5, n.2, p.177-200, ago. 2011.

essência é insustentável, pois temos que levar em conta que toda produção é ao mesmo tempo destruição, ou seja, trata-se da chamada produção destrutiva.

Portanto, esta atividade humana deve ser entendida no contexto geral de consumo e produção da natureza, ou seja, consumo e produção de espaço, ou, neste estudo, a produção do espaço rural no assentamento Sul Bonito.

Rodrigues (2001, p.32) propõe que o turismo deve ser caracterizado como uma atividade que envolve a indústria, o serviço e a natureza como paisagem-mercadoria, porque todos estes setores encontram-se intimamente imbricados na prática turística, constituindo, sob nosso entender, o território turístico.

Para Lucato Moretti (2002), esta atividade está inserida no processo geral de produção capitalista, sendo uma das formas encontradas pelo capital para sua reprodução. Portanto, trata-se de uma atividade complexa e inserida num processo geral de acumulação. Neste contexto, a atividade turística gera a ideia de desenvolvimento local, principalmente para áreas que passam por uma estagnação econômica e apresentam características indicadoras da possibilidade do consumo através da atividade turística (elementos naturais e/ou culturais), possibilitando, por meio do turismo, a inserção destes lugares no mundo global.

Em pesquisas recentes realizadas no Mato Grosso do Sul ${ }^{3}$ (especificamente no Pantanal e em Bonito), foi identificada a distância existente entre a geração de riqueza e a sua distribuição. Em tais lugares, a inserção na rede turística global não significou a geração de melhorias nas condições gerais de vida da população, como nos setores da educação, saúde, moradia, infra-estrutura urbana, dentre outros.

Nas andanças movidas pelas pesquisas no Mato Grosso do Sul, nos deparamos constantemente com práticas sociais que escapam dos padrões e

3 Pesquisas realizadas no Grupo de Pesquisa Território e Ambiente coordenadas por Edvaldo Cesar Moretti, com financiamento do CNPq e FUNDECT-MS. 
normas impostas pelo olhar científico, uma delas, e que propicia reflexões, é a prática turística realizada e/ou em construção nos assentamentos rurais.

No Mato Grosso do Sul, historicamente, a terra é controlada pela produção voltada ao mercado internacional, balizada por muito tempo no binômio gado e soja, aos quais se junta a produção da cana-de-açúcar, centrada no controle dos elementos naturais - solo, água, luz - com aplicação intensiva de produtos químicos visando ao aumento constante da produtividade.

Esta estrutura agrária dominante produziu, além de intensa pilhagem ambiental, um contingente expressivo de trabalhadores sem terra, que há tempos lutam pelo direito à posse e à produção na terra. São migrantes pobres, indígenas, quilombolas, entre outros, que com sua organização conseguem, mesmo que de maneira parcial, a implantação de assentamentos rurais.

A tabela a seguir aponta para o expressivo contingente de assentados no Mato Grosso do Sul.

Tabela 1 - Quantitativo de assentamentos e de assentados no Mato Grosso do Sul

\begin{tabular}{lrrr}
\hline $\begin{array}{l}\text { Projetos de assentamentos/ } \\
\text { reassentamentos }\end{array}$ & Quantidades & Famílias (no) & Área (ha.) \\
\hline Criados pelo INCRA & 177 & 29.811 & $669.986,6616$ \\
Criados pelo MS & 08 & 694 & $14.400,8050$ \\
\hline Total geral (I + II) & $\mathbf{1 8 5}$ & $\mathbf{3 0 . 5 0 5}$ & $\mathbf{6 8 4 . 3 8 7 , 4 6 6 6}$ \\
\hline \multicolumn{2}{c}{ Fonte: Divisão de Obtenção de Terras e Implantação de Projetos/SIPRA (atualizado em } \\
\multicolumn{2}{c}{ 24/06/10) }
\end{tabular}

Especificamente, o município de Itaquiraí também recebeu um número expressivo de assentamentos, mas os problemas são latentes, com destaque para a ausência de uma política pública direcionada à produção e à comercialização dos produtos produzidos pelos assentados. 
Tabela 2 - Assentamentos implantados no município de Itaquiraí

\begin{tabular}{cccc}
\hline Itaquiraí & Ano & \multicolumn{3}{c}{ Famílias (nº) } & Área (ha.) \\
\hline Indaiá & $20 / 10 / 1989$ & 633 & $6.375,9385$ \\
Sul Bonito & $09 / 10 / 1996$ & 421 & $7.340,6719$ \\
Guaçu & $29 / 12 / 1997$ & 134 & $2.678,9794$ \\
Santa Rosa & $29 / 12 / 1997$ & 200 & $4.048,1606$ \\
Tamakavi & $04 / 12 / 1998$ & 120 & $3.383,5670$ \\
Boa Sorte & $23 / 12 / 1998$ & 65 & $1.498,0306$ \\
Aliança & $29 / 12 / 2000$ & 38 & $1.101,6902$ \\
Lua Branca & $03 / 04 / 2001$ & 124 & $2.425,3962$ \\
Santo Antonio & $17 / 07 / 2007$ & 607 & $9.627,8274$ \\
Itaquiraí & $17 / 07 / 2007$ & 255 & $3.232,9883$ \\
Caburey & $17 / 07 / 2007$ & 127 & $1.848,2303$ \\
Foz do rio Amambaí & $17 / 07 / 2007$ & 199 & $2.210,0210$ \\
\hline Total & & $\mathbf{2 . 9 2 3}$ & \\
\hline
\end{tabular}

Fonte: INCRA/MS

Entre esses assentamentos rurais no município de Itaquiraí está o Sul Bonito, implantado em 1996, com 421 famílias. No assentamento, os grupos organizados se dividem em contrários e favoráveis à implantação do turismo. Mesmo construído o discurso de possibilidade de aumento de renda e permanência na terra através da atividade turística, as famílias assentadas são firmes em suas proposições da organização da atividade estar sob o controle dos assentados.

\section{A Prática Turística no Assentamento: de Prainha para Praia da Amizade}

No assentamento rural Sul Bonito, a discussão sobre a implantação da atividade turística está presente na agenda dos grupos organizados do assentamento, sendo incentivada pela prefeitura municipal de Itaquiraí. A 
motivação para a inserção da atividade turística no assentamento é decorrente de parcela dos lotes estarem localizados às margens do Rio Paraná, cuja utilização, historicamente, é feita pelos moradores das proximidades para o lazer, com destaque para a pesca amadora e o banho de rio.

O poder público, associado a empresas privadas, se apropria do sentido de pertencimento que a população local construiu referente a trechos do rio, principalmente para práticas associadas ao lazer, e produz a Praia da Amizade, como é conhecido localmente um pequeno trecho da margem do Rio Paraná, localizada dentro de dois lotes do assentamento rural Sul Bonito, a aproximadamente $21 \mathrm{~km}$ de distância da cidade de Itaquiraí.

Antes da implantação do assentamento Sul Bonito, a área reconhecida como "'prainha" era utilizada para o desembarque de barcos de pescadores que visitavam o rio Paraná, e também para momentos de lazer, como os banhos de rio de final de semana praticados por parcelas da população de Itaquiraí.

Quando houve a implantação do assentamento, a área dos lotes onde está localizada a "prainha" foi destinada como área de lazer comunitária do Sul Bonito, planejada como área de lazer comum, com uso livre para as famílias assentadas.

Concretamente, a área é apropriada pelo novo sonho desenvolvimentista moderno, ou seja, a atividade turística na forma de eventos e festas relacionadas ao uso das águas do Rio Paraná. Sob tal perspectiva, o poder público municipal iniciou um processo de estruturação e edificação da "prainha" juntamente com a realização da Itaquipesca, festa esportiva que tem como principal atrativo a pesca no rio Paraná, atraindo visitantes e pescadores de várias cidades do estado do Mato Grosso do Sul e Paraná. A partir de então, foi criada a Praia da Amizade.

Com a intervenção do poder público na apropriação do uso das margens do rio no trecho do assentamento Sul Bonito, ocorreram transformações na paisagem. A Praia da Amizade conta com infra-estrutura para camping, com churrasqueiras, pias de louça com água encanada, lixeiras, tomadas elétricas, 
ISSN: $1982-6125$

banheiros com chuveiro elétrico e vestiários, conjuntos sanitários, rede de energia com disposição de lâmpadas por todo o ambiente, rampa para embarque e desembarque para barcos e lanchas (Schneider, 2009, p.112).

Na proposta de construção do atrativo turístico na Praia da Amizade, foi estruturada uma trilha para caminhada na mata, às margens do rio Paraná, denominada Trilha Ecológica do Bugio, relacionando o atrativo com a ideia de contato com a natureza.

Também relacionado à proposta de produzir estrutura de atendimento turístico às margens do rio, foi implantada uma lanchonete que adquire importância para a reflexão sobre a prática turística no Sul Bonito ao ser utilizada como compensação ao proprietário que teve seu lote diretamente "ocupado" pela produção da Praia da Amizade. O assentado no lote transformado em Praia da Amizade ficou com uma parte do lote, destinado ao plantio de eucalipto, e obtém sua renda por meio da administração da lanchonete e comercialização de alimentos e bebidas.

Na época da Itaquipesca, outra parte do seu lote é locada pela prefeitura para organizar o estacionamento para ônibus e veículos particulares. Complementando as ações públicas para a produção do atrativo, a prefeitura municipal de Itaquiraí implantou uma estrada dentro do lote para facilitar o fluxo de veículos durante os dias da festa.

Os estudos de Camaratta (2006) apresentam o turismo como uma prática social e demonstram como essa atividade pode se apropriar e consolidar os territórios. Uma das formas de apropriação dos territórios pela atividade turística se dá através da intervenção do poder político e econômico.

el territorio se va definiendo a medida de los intereses y lugares, las demarcaciones surgen ante variados tipos de acciones e intereses de los hombres o agentes económicos donde lo que se consolida son acciones de poder político y económico inducidos por los negocios, promociones y eventos (Camaratta, 2006, p.358).

A construção do espaço turístico Praia da Amizade se deve à intervenção direta do poder público local na construção de um atrativo turístico. Os 
assentados não participam, não decidem e não são beneficiados pela turistificação da margem do rio.

Em estudo realizado em Anaurilândia e Fátima do Sul, municípios do Mato Grosso do Sul, Ocon (2009, p.61) adverte sobre os pontos negativos da inserção da atividade turística em pequenos municípios como política de desenvolvimento baseada em modelos externos implantados com a áurea da geração de emprego e renda, e alerta para a impossibilidade de participação dos atores sociais no que se refere à decisão sobre a inserção de empreendimentos turísticos, desconsiderando, assim, o movimento de produção e construção das práticas sociais. O autor afirma que,

Em geral, isto acontece, quando a atividade turística é inserida como única e exclusivamente alternativa de "desenvolvimento" econômico para paises, regiões, estados e municípios que se encontram relativamente estagnadas em sua economia, e o turismo aparece como prática desenvolvimentista (Ocon, 2009, p.62).

No assentamento Sul Bonito, a implantação do atrativo turístico ocorre sem a participação das famílias assentadas. A tomada de decisões sobre o turismo no assentamento parte do poder público local através da Gerência de Desenvolvimento Econômico e Turismo, responsável pelo planejamento da atividade a partir da privatização, com incentivos para a construção de hotel na área urbana de Itaquiraí e a terceirização do uso da Praia da Amizade, por exemplo.

Como contraponto a esse processo de privatização do público, parcelas dos assentados resistem e apontam para a necessidade de repensar o modelo de turismo imposto no assentamento.

Os assentados possuem um entendimento sobre a atratividade turística na Praia da Amizade que contrapõe as propostas do poder público. Ao 
SILVA, Daiane Alencar da; MORETTI, Edvaldo Cesar. O território em movimento no assentamento rural Sul Bonito em Itaquiraí/MS: a prática turística na Praia da Amizade. Revista Brasileira de Pesquisa em Turismo.

v.5, n.2, p.177-200, ago. 2011.

ISSN: $1982-6125$

responder sobre o potencial turístico da Praia da Amizade uma assentada ${ }^{4}$ faz uma leitura da forma de produção do atrativo:

Se a gente for pensar bem não é uma praia, é apenas o rio passando, abriram mais a mata, vamos dizer assim, jogaram areia lá, pra parte de esporte, salão, essas coisas, mas se a gente for tirar a noção mesmo não é uma praia. Eu penso desse jeito. Mas é uma coisa assim que você sai final de semana que você pode distrair, mas é diferente de uma praia.

Com relação a esse estranhamento sobre o lugar, nesse caso, a assentada não visualiza uma "praia", mas simplesmente um rio passando e areia colocada em uma de suas margens. Cruz (2000, p.16) afirma que

A competitividade espacial exige a racionalidade das formas de condicionamento, de utilização e, finalmente, de apropriação dos espaços, assegurando aos lugares alguma hegemonia nesse contexto de mercados e lugares globalizados.

Da capacidade dos atores hegemônicos de intervir sobre o ordenamento e reordenamento de territórios, numa escala global, resulta, entre outras coisas, uma crescente artificialidade de objetos e de ações. Esta pode gerar uma sensação de estranhamento, por parte dos indivíduos, do seu entorno.

Sobre o uso que os assentados fazem da Praia da Amizade, a entrevistada afirmou que para os assentados aquela área não é tão representativa, já que eles estão acostumados com o lugar "a gente é acostumada ir lá, mesma coisa, não muda nada. É comum. Você vai lá, passa as horas, mas não tem aquela coisa que as pessoas falam assim 'ai eu vou na prainha' aquela coisa, não tem isso". Ela completa:

Ah sim, uma vez no final de semana, faz um churrasquinho, uma coisa assim ou outra. Mais passa tempo mesmo. Porque aqui não tem muitas opções pra você sair, aquela coisa toda, a única coisa que a gente tem é a prainha e festas nas comunidades que a gente tem e ta sempre participando.

4 Entrevista realizada com assentada, nome mantido em sigilo oculto nesta publicação, concedida aos autores em trabalho de campo no assentamento Sul Bonito, no dia 13 de abril de 2010. 
Quando a assentada fala sobre as festas nas comunidades, está se referindo às festas religiosas que homenageiam os santos presentes nas capelas do assentamento. Geralmente, são festas que começam no sábado à noite, com baile, e continuam no domingo pela manhã com almoço à base de churrasco, e à tarde com leilões e bingo para arrecadação de dinheiro para a capela da comunidade. O dinheiro arrecadado é normalmente empregado na construção ou manutenção da estrutura da capela, ou utilizado para ajudar alguém da comunidade que esteja passando por dificuldades em relação à saúde, como explica um assentado:

É dividido assim: cada capela tem uma data no ano, igual sábado e domingo passado teve aqui na nossa comunidade Sagrado Coração de Jesus. Então o que acontece, tem o bingo, tem o almoço, tem o baile, então distrai. Além de você distrair, você também ajuda a comunidade. Na parte de organização, a gente ta envolvido também e ajudando uma coisa e outra, não pode deixar só pra uma pessoa, tem que estar ali sempre trabalhando junto.

Entende-se a manifestação desses festejos religiosos como uma forma da comunidade permanecer com seus costumes; costumes estes que fazem parte da história de vida dos assentados. Sobre essa relação das famílias assentadas com o meio rural e com as relações sociais reproduzidas nesse espaço, Wanderley (2009, p.297) afirma que

\begin{abstract}
O meio rural é entendido como um espaço suporte de relações sociais específicas, que se constroem, se reproduzem ou se redefinem sobre este mesmo espaço e que, portanto, o conformam enquanto um singular espaço de vida. (...) o espaço rural é socialmente construído pelos seus habitantes, em função das relações fundadas nos laços de parentesco e de vizinhança, e isto, tanto ao nível da vida cotidiana, quanto do ritmo dos acontecimentos que determinam os ciclos da vida familiar, tais como, nascimentos, casamentos e mortes e, ainda, no que se refere ao calendário das manifestações de ordem cultural e religiosa.
\end{abstract}

Mas essa falta de interesse pela Praia da Amizade e a atividade turística no local não é compartilhada por todos os assentados. Existem assentados que entendem a "prainha" como a conquista de luta, sendo esta indicada com orgulho pelos assentados. Ao ser perguntado sobre o potencial turístico do 
SILVA, Daiane Alencar da; MORETTI, Edvaldo Cesar. O território em movimento no assentamento rural Sul Bonito em Itaquiraí/MS: a prática turística na Praia da Amizade. Revista Brasileira de Pesquisa em Turismo.

v.5, n.2, p.177-200, ago. 2011.

ISSN: $1982-6125$

assentamento, um assentado ${ }^{5}$ do grupo coletivo expressa claramente esse sentimento.

Turista nós temos aqui, no assentamento nós temos uma grande praia, a Praia da Amizade, esse é o grande foco do turismo. Isso é um orgulho pro assentamento. Nós fizemos aqui 10 anos de assentado e fizemos um dia cultural lá. Teve show, fizemos churrasco... Principal é divulgar, a imprensa veio, todos os políticos veio, temos um lado positivo do assentamento. Essa Praia da Amizade é o orgulho nosso.

Essa visão é compartilhada por outro assentado, liderança do grupo coletivo, e pôde ser vista durante a entrevista realizada no dia 16 de dezembro de 2006 na festa de comemoração dos 10 anos de assentamento Sul Bonito na Praia da Amizade.

\begin{abstract}
Essa Praia da Amizade é resultado das conquistas do povo, da conquista do sem-terra. Então aqui ta dentro do assentamento também, né, foi uma área que foi destinada aqui, é tipo áreas comunitárias, que virou uma área de turismo, certo. Então isso aqui se não fosse a luta do povo, se não fosse sete despejo de sem-terra, sete ocupação dessa área aqui, isso aqui não existia, aliás, o povo jamais ia te acesso de conhece isso aqui, que se chama essas riquezas naturais, e um pouco de preservação ainda que a gente tem trabalhado e o município ta se preocupando com isso, de como utilizar o recurso natural pra questão do lazer, mas também preservar, nós já decidimos que as comunidades aqui ninguém toca numa árvore dessa que tem aqui.
\end{abstract}

Percebe-se que os assentados com participação mais ativa no Movimento dos Sem Terra (MST), e que fazem parte do grupo coletivo Chico Mendes, apresentam olhares diferenciados sobre a questão, entendendo que há necessidade de divulgar a Praia da Amizade e promover a área como atrativo turístico, visando o desenvolvimento conjunto do assentamento.

Segundo entrevista com o representante da Gerência de Desenvolvimento Econômico e Turismo na Prefeitura de Itaquiraí/MS ${ }^{6}$, alguns

5 Entrevista realizada com assentado do Grupo Coletivo, concedida a autora em trabalho de campo no assentamento Sul Bonito, no dia 13 de abril de 2010.

6 Entrevista realizada com a Gerência de Desenvolvimento Econômico e Turismo da Prefeitura Municipal de Itaquiraí, concedida a autora em trabalho de campo no dia 12 de abril de 2010. 
SILVA, Daiane Alencar da; MORETTI, Edvaldo Cesar. O território em movimento no assentamento rural Sul Bonito em Itaquiraí/MS: a prática turística na Praia da Amizade. Revista Brasileira de Pesquisa em Turismo. v.5, n.2, p.177-200, ago. 2011.

ISSN: $1982-6125$

assentados não manifestam interesse em participar da atividade turística no assentamento, se recusando, por vezes, a fazer parte da organização para a promoção e o desenvolvimento do turismo.

Tem um grupo, uma Colônia de Pescadores (Porto Santo Antonio) lá, que a gente discutiu para eles começarem a fazer a produção a partir do peixe, pra que a gente pudesse estimular o visitante a ir até lá pra comprar o peixe, comprar os derivados, os embutidos do peixe. Levamos curso de capacitação promovido pela prefeitura, pago pela prefeitura e depois do curso, simplesmente não fizeram nada. Essa é uma dificuldade que a gente tem mesmo de estimular as pessoas, por conta que o leite que dá pra eles o arroz e o feijão, ta bom, entendeu? Essa é a verdade.

Para justificar o não envolvimento dos assentados na organização e desenvolvimento do turismo no assentamento, a representante do poder público aponta os motivos do desinteresse dos assentados pela prática turística no assentamento.

\begin{abstract}
Até um dia a gente descobriu porque disso, discutindo aqui com o pessoal da agricultura, os técnicos, e eu meio indignada com isso, ai ele falou isso: "Val, na verdade você pergunta pra eles qual é o seu maior sonho? E ele vai responder pra você: é ter a terra". E ponto, ele não quer nada mais do que ter a terra. Esse técnico fez a gente ver o outro lado que a gente não queria enxergar, que eles não têm sonhos, o sonho dele era ter a terra e ele já alcançou, ele já chegou ao limite do que ele queria pra ele. Então ele nunca pensou "eu quero ter a terra, produzir, daqui eu quero ter uma vida com qualidade, ter uma vida de conforto", não, ele queria ter a terra, e isso já alcançou. Então talvez isso tenha sido um dos problemas, e a gente tem dificuldade em avançar mesmo com projetos.
\end{abstract}

Entende-se, nesse trabalho, que cada assentado traz consigo uma trajetória de vida diferente. O assentamento acaba sendo um lugar onde esses sujeitos se encontram para reproduzirem seus modos de vida que foram, por vezes, interrompidos em outros lugares. O assentado carrega um misto de valores e aspectos de modos de vida diferente do lugar onde serão assentados. Para Bosi (1983), a reconstrução do sentimento de pertencimento ao lugar, agora um novo lugar, é uma das condições mais difíceis para o ser humano. 
Nesse processo de desenraizamento e de busca de enraizamento, estes agricultores assentados, na condição de migrantes, vêem suas múltiplas raízes se partirem ao perderem sua paisagem natal, a roça, as águas, as matas, a casa, os vizinhos, as festas, a sua maneira de vestir, de louvar a Deus (Bosi, 1983 apud Medeiros, 2006, p.283).

Devemos levar em conta as exceções, mas a maioria dos assentados é de raízes rurais. Trata-se de ex-proprietários de terras, arrendatários, meeiros, etc., que possuem um vínculo maior com a terra, com a produção para a sobrevivência. Esses assentados, então, não almejam fazer parte de nada que saia fora do seu ritmo de vida. No caso dos pescadores da Colônia Santo Antonio, onde a vida se faz ao redor do rio Paraná, e a família ao redor do pescado, isso já é suficiente. São sujeitos que foram constituídos dentro dessa realidade e não thes interessa interromper o ciclo estabelecido com a família e o meio onde vivem para receberem visitantes, muito menos ficar a mercê de uma produção inserida de cima para baixo a fim de atender o estranho, o turista.

Esses assentados que preferem não se sujeitar ao que lhes é imposto como forma de produzir e permanecer na terra são considerados grupos ruins, já que os grupos bons são aqueles que tentam se inserir na lógica de produtividade, principalmente a ligada ao turismo.

Claro que a gente pega grupos que são bons, que avançam. Tem grupo que vem aqui e pede pra gente ver alguma coisa pra eles, a gente senta, propõem curso disso, daquilo, mas ai eles colocam um monte de dificuldade, não que isso a gente não pode fazer lá porque não vai dar certo. "Ah, vamos levar embutidos de suínos, não mais isso precisa dos homens pra matar os porcos, vamos levar curso de não sei o que, ah não, mas isso vai dar trabalho pra vender". Tem umas pessoas que a gente já sabe que não vai pra lugar nenhum. É isso que o Sr. Aldo fala de visitar, conhecer, saber se a pessoa tem vontade porque é muito difícil de mexer (Oliveira, 2010).

Coriolano (2006, p.374) alerta que a maioria da população local, alienada pelo consumo, adapta-se ao sistema de produção capitalista convencional e o turismo caracteriza-se como uma prática social causadora de divisão interna nas comunidades. Segundo ele, a transformação e os 
SILVA, Daiane Alencar da; MORETTI, Edvaldo Cesar. O território em movimento no assentamento rural Sul Bonito em Itaquiraí/MS: a prática turística na Praia da Amizade. Revista Brasileira de Pesquisa em Turismo. v.5, n.2, p.177-200, ago. 2011.

ISSN: $1982-6125$

resultados genéricos e sustentados demandam tempo para serem obtidos por tais comunidades.

O poder público, diferentemente da proposição de Coriolano que identifica a necessidade de tempo e amadurecimento para a prática turística, aponta como proposta desenvolvimentista para o município o aceleramento do processo de implantação de roteiros turísticos específicos para o turismo rural, conforme aponta a representante da Gerência de Desenvolvimento Econômico e Turismo na Prefeitura de Itaquiraí/ MS

Pra essa região aqui nos tínhamos até pensado, até foi discutido, foi traçado no plano de ação, [...] que é o turismo na agricultura familiar, turismo rural dentro da agricultura familiar, nessa região aqui.

A gente teria que trabalhar com a confecção de doce, fazer uma rota até a praia, que a gente acha complicado. E a Praia da Amizade que fica dentro do Sul Bonito, então na verdade para o Sul Bonito de turismo é movimentar a praia e incrementar o projeto que a gente tem pra lá, que acontece, é normal já o fluxo no final de ano, de temporada de verão, a Praia da Amizade já serve. Agora a comunidade ainda não tem retorno disso, justamente porque a gente não consegue organizar.

Continuando, o representante do poder público, fortalece a perspectiva de intervenção na valorização turística da área e afirma:

É preciso melhorar a estrutura da Praia. Sem melhorar a estrutura não é possível pensar em projetos mais ousados, porque ali vai ser um grande ponto de Desenvolvimento Econômico, quando se pensa que vamos precisar de guias, vamos precisar de gente que pilote os barcos para os turistas, a questão da gastronomia, então pensamos numa série de projetos para o local. Nós já estamos discutindo a questão da colônia de pescadores para realizar ali um processo de revitalização para recuperar a imagem do antigo Porto Santo Antonio, e criar ali um ponto de turismo também, vamos apresentar esse plano no papel para estar trazendo recursos do governo federal, criando ali um point para barqueiros e recuperando a imagem do pescador aliado ao Porto. Já estivemos debatendo sobre esse plano com o superintendente da Secretaria Nacional da Pesca em Campo Grande, vamos estar em breve debatendo com os pescadores sobre o assunto.

A esse respeito, as ações que se pretende realizar na área estão relacionadas, principalmente, à qualificação dos moradores locais para as eventuais prestações de serviços, e também, estas ações do poder público 
revelam que os projetos turísticos estão recebendo um incentivo especial do governo federal, com disposição de recursos financeiros e apoio técnico.

Devido a esses incentivos, há uma parceria sendo realizada entre a Prefeitura Municipal de Itaquiraí gerência e a rede TUR no Estado do Paraná, entidade ligada à Universidade Estadual de Maringá, assim como a constituição de macroações turísticas e do Fórum de Turismo Regional, elaborado junto com todos os municípios da região Cone Sul. Nas palavras do representante da rede TUR/ Fórum de Turismo Regional a proposta da parceria tem como centralidade:

\begin{abstract}
A ideia com a rede TUR é aproveitar do rio que também tem uma influência muito forte no noroeste do Paraná, para desenvolver um projeto relacionado à pesca, isso já está quase fechado, que vai ser a tríplice fronteira entre os Estados do Paraná, Mato Grosso do Sul e São Paulo, já estamos discutindo calendários de festas ligadas à água, além disso, eles têm um projeto para vender pacotes turísticos incluindo a Praia da Amizade, aí devemos incluir a gastronomia, o artesanato, e o espaço, porque, eles não têm um espaço como o nosso, que une a água, a sombra, a areia, a infra-estrutura, então eles ficam extremamente empolgados, tudo isso nós vamos estar explorando o Parque Nacional de Ilha Grande, porque pra nós é um lote muito grande de divulgação, enfim, quem tem um espaço desse próximo não pode deixar de explorar, pois é um Parque conhecido nacionalmente, mas nós temos que respeitar o Plano de Manejo do Parque, então tudo isso nos estamos pensando e construindo.
\end{abstract}

A atividade turística em Itaquiraí, como esclarece Oliveira (2009), não se restringe a essas propostas. Contudo, para a área ribeirinha do município, a pesca, o camping, a gastronomia e a contemplação das "belezas" naturais seriam os maiores atrativos. O turismo é visto no município como atividade econômica, promotora de desenvolvimento local, nas palavras da entrevistada: "estamos trabalhando com a diversidade da economia local, para não ficarmos tão vulneráveis à febre aftosa, à secas, estamos criando alternativas de desenvolvimento econômico, uma delas é o turismo" (Schneider, 2009, p.114).

Com relação à clientela que se espera conquistar, Oliveira (2009) afirma:

Quando a gente pensa, a principio no turista, a gente não pode focar o turista que vem no Mato Grosso do Sul em alta escala, aquele que vem 
SILVA, Daiane Alencar da; MORETTI, Edvaldo Cesar. O território em movimento no assentamento rural Sul Bonito em Itaquiraí/MS: a prática turística na Praia da Amizade. Revista Brasileira de Pesquisa em Turismo.

v.5, n.2, p.177-200, ago. 2011.

ISSN: $1982-6125$

pra Campo Grande para ser distribuído pelo estado, porque ele vem pra conhecer o Pantanal, Bonito, o Trem do Pantanal, Corumbá, nós não esperamos que as operadoras atraiam para nós esse turista. Então nós temos que buscar um turista diferenciado para a nossa região Cone Sul, por isso estamos fazendo essa parceria com a rede TUR, para atrair o turista do Paraná, principalmente. Obviamente queremos atrair turistas de Dourados, Nova Andradina, ou seja, da região próxima de Itaquiraí, mas não podemos ficar só nisso, também. Então a gente tem essa conversa com a rede Tur para atrair turista do Paraná, e principalmente explorar a questão da pesca, porque é forte isso. O pescador, ele busca espaço, ele arruma dinheiro pra montar essas pescarias, então a gente foca muito a questão da pesca, não só no período de Itaquipesca, mas trazer o pescador pra passar finais de semana, e ai a gente tem algo melhor pra vender, que é a àrea da Praia da Amizade quando a gente tem uma estrutura que ele pode trazer a família pra aproveitar o final de semana, e ele ficar pescando, pois a maioria dos espaços não oferece isso. E do Estado de São Paulo também, por isso o projeto da tríplice fronteira, que está bem avançado essa discussão com o pessoal da rede TUR (noroeste do PR) (Schneider, 2009, p.114).

A gerente relata que a cidade é carente de infraestrutura para receber o fluxo turístico:

[...] não temos infraestrutura pronta, por isso não vamos fazer loucura, são planos de longo prazo. Mas só pelo fato da gerência deixar estruturado o setor do turismo com um plano aprovado em Lei, a contribuição está dada ao município, os futuros gestores é que vão colocar em prática os planos.

Os hotéis que a cidade de Itaquiraí possui são todos de pequeno porte, não comportando grandes demandas. Segundo Schneider (2009, p.109) este município possui dois hoteis, um com 19, outro com 18 apartamentos, todos com TV, Ar ou Ventilador, cama de casal e solteiro, somando 37 leitos que não são capazes de suprir a demanda.

Em 2011, um novo hotel está em fase adiantada de construção, sendo os proprietários sócios do hotel a atual prefeita e o vice-prefeito do município de Itaquiraí. A princípio, o hotel contará com 38 leitos, segundo o vice-prefeito, e será ampliado posteriormente. O empreendimento é financiado pelo Banco do Brasil, com os recursos adquiridos através do Fundo Constitucional do Centro Oeste - FCO. 
Tendo em vista o aumento do fluxo de visitantes na cidade por causa do atrativo da Praia da Amizade, empresários da região estão ampliando e melhorando os hotéis existentes na cidade.

A esse respeito, por exemplo, há um empresário comerciante do município com grande interesse em investir na construção de uma pousada na região próxima ao rio Paraná. Entretanto, este espera por uma avaliação sobre os impactos ambientais e também o inventário turístico que irá ser realizado pela Fundação de Turismo do Estado, dentro do planejamento regional (Schneider, 2009, p.115).

A margem do rio Paraná, que inicialmente foi designada como espaço de lazer comunitário para os assentados, está sendo apropriada pelo poder público local para a prática da atividade turística, com a intenção de privatizar essa área através de empresas que deverão controlar o acesso de pessoas ao local. Oliveira esclarece:

A gente não precisa promover nada as pessoas vêm, oriundas da região aqui, do Cone Sul, mas também do Paraná, nós temos recebido muitos pescadores do Paraná, tem uns grupos de uma cidade do Paraná que eles ficam dez dias, montam barracas e ficam dez dias por ali, sem custo nenhum. A gente não pode cobrar, porque a gente não tem ela regulamentada. O COMTUR discute a possibilidade de cobrar uma taxa de permanência, mas para isso a gente tem que estar com ela regulamentada.

É preciso frisar que a Praia da Amizade está tendo o mesmo destino de outros atrativos turísticos no mundo, que acabam sendo incorporados pela lógica mercadológica do capitalismo através da privatização desses espaços que, inicialmente, são de uso público.

Pode-se observar a privatização de praias, por exemplo, no litoral do nordeste do Brasil, onde grandes empreendimentos denominados de resorts se apropriam das margens costeiras permitindo somente o acesso de pessoas que são hóspedes do hotel. Ou a privatização de rios, como é o caso de Bonito-MS, onde os proprietários de terras situadas às margens dos rios de águas cristalinas, como o rio Formoso, restringem o acesso de pessoas por meio do 
pagamento de taxas de permanência no local, criando, assim, balneários às margens dos rios.

Esses são exemplos mínimos de privatização de espaços públicos através da apropriação do uso e consumo da natureza pela lógica capitalista, semelhantes ao caso da Praia da Amizade em Itaquiraí.

O turismo se apropria da ideia de natureza reencantada para espetacularizar a atitude de contemplação e assim promove a construção do espaço de acordo com os interesses de consumo do mesmo. Cruz (2000, p.09) acrescenta que o modo como se dá a apropriação de uma determinada parte do espaço geográfico pelo turismo depende da política pública de turismo implantada no lugar, pois a política pública de turismo será a responsável pelo estabelecimento de metas e diretrizes que orientarão o desenvolvimento socioespacial da atividade.

No entanto, essa área da "prainha" apresenta irregularidades que têm preocupado o poder público local, como a falta de licenciamento ambiental para funcionar como ponto turístico e de lazer. Isso remonta desde a época da demarcação dos lotes para o assentamento Sul Bonito.

Quando o INCRA delimitou a área do assentamento, não levou em consideração a área de preservação ambiental necessária às margens do rio Paraná. Portanto, as áreas de encosta do rio foram loteadas pelo INCRA sem respeitar a distância $(500 \mathrm{~m})$ de mata ciliar correspondeste ao rio.

$\mathrm{Na}$ área ribeirinha de acesso ao público, estão exatos 48 lotes do Assentamento Sul Bonito, além do antigo Porto Santo Antônio, onde existem mais de 20 famílias de pescadores residentes. Desses 48 lotes, 03 estão onde se estabelece a Praia da Amizade, sendo nesse ambiente (zona de amortecimento ao Parque) que acontece grande parte das festividades, estando aí localizada a sede permanente da Itaquipesca, um tradicional evento de competição de pesca que será abordado mais adiante (Schneider, 2009, p.110-111).

Devido a isso, o IBAMA não pode licenciar a área porque esta não mantém os 500 metros da margem do rio Paraná, o que é exigido pela 
legislação ambiental para esse caso. Em 1989, a Lei no 7.803 instituiu que a largura das áreas de preservação permanente deveria ser de quinhentos metros de largura para cursos d'água com largura superior a seiscentos metros, enquadrando-se, nesse caso, o rio Paraná. Porém, essa legislação não foi respeitada no assentamento, ocasionando sérios problemas ambientais na área.

A prefeitura do município ainda tenta regularizar a situação da "prainha", mas o caso torna-se mais complicado porque os assentados não possuem o título e a matrícula do lote. Todo o assentamento Sul Bonito está registrado sob uma matrícula única no INCRA, impossibilitando, nesse caso, a venda da propriedade, como explicou a gerente do Núcleo de Desenvolvimento Econômico e Turismo do município:

A gente já solicitou do INCRA, mas é muito difícil a situação lá porque ela pertence a um assentado. [...] É muito complicado, a gente não consegue comprar do proprietário pra legalizar a Praia, porque ele não pode vender, que não é dele, ele não tem o título. Ninguém tem título lá ainda. E o problema do Sul Bonito ainda é mais complicado do que os outros lugares, porque o Sul Bonito ta numa matrícula só no INCRA, ela não foi desmembrada ainda. O Indaiá já foi desmembrado, mas o Sul Bonito ainda é uma matrícula só. Então você não consegue chegar lá e resolver o problema daquela área só.

Para resolver a situação da matrícula do Sul Bonito, o INCRA precisa que a prefeitura faça o georreferenciamento de todo o assentamento, ou seja 422 lotes. O valor de tal estudo gira em torno de $\mathrm{R} \$ \mathbf{2 . 5 0 0 , 0 0}$ por lote e a prefeitura alega não ter dinheiro para resolver a situação, ficando, assim, sem poder licenciar a Praia da Amizade.

Além disso, não poderia ser licenciada apenas a área da Praia da Amizade, mas sim todos os lotes que margeiam o rio Paraná, totalizando 48 lotes, segundo a gerente de Desenvolvimento Econômico e Turismo da prefeitura. Então, levanta-se a questão: para onde serão encaminhados os assentados que tiverem seus lotes irregulares e precisarem ser removidos para a regularização da área? Esse fato vem preocupando tanto o poder público quanto os assentados envolvidos nessa problemática, justamente porque 
ISSN: $1982-6125$

alguns deles desenvolveram planejamentos de usufruir a sua localização para extrair renda extra da propriedade, como é o caso de um assentado que planeja construir uma pousada em seu lote, dando aos hóspedes a possibilidade de chegarem até a "prainha" através de um passeio de barco, já que seu lote está às margens do rio.

Também o proprietário do lote onde se encontra a Praia da Amizade planeja construir uma pousada em sua área. Este proprietário alega ter dificuldade para respeitar a distância mínima exigida pela legislação ambiental de 500 metros da margem do rio.

Caso aconteça a remoção das famílias de seus lotes para que haja o licenciamento da área, esses assentados serão prejudicados em seus planos, mesmo sabendo que tal fato foi ocasionado pela conduta irregular do INCRA ao permitir o uso da área como sendo pertencente ao lote.

É uma questão complicada. Já existem projetos urbanísticos para a "prainha", mas que não podem ser executados por falta de licenciamento ambiental, sendo que, para o licenciamento, é necessária a documentação da área.

De acordo com a gerente de Desenvolvimento:

Hoje nosso maior espaço para a exploração do turismo é a Praia da Amizade, e a partir dela pensamos em estender para passeios de barco, visitas nas ilhas, entre outras atividades [...], mas enquanto a área não é regularizada não podemos fazer nada de mais ousado a não ser manter a estrutura que já temos ali ${ }^{7}$.

Nessa entrevista, o representante do poder público apresenta as intenções do poder público local para esta área:

Nós temos um projeto arquitetônico maravilhoso para a Praia da Amizade, porém dependemos dessa regularização, e como o INCRA vai regularizar a praia (03 lotes) e deixar os outros 45 lotes sem a devida regularização. Estamos tentando resolver esse problema. Porque ali a Prefeitura não pode nem desapropriar, nem comprar as áreas, pois não

7 Entrevista realizada por Schneider em trabalho de campo no dia 11 de maio de 2009. 
SILVA, Daiane Alencar da; MORETTI, Edvaldo Cesar. O território em movimento no assentamento rural Sul Bonito em Itaquiraí/MS: a prática turística na Praia da Amizade. Revista Brasileira de Pesquisa em Turismo.

v.5, n.2, p.177-200, ago. 2011.

ISSN: $1982-6125$

há títulos de propriedade das terras, sendo assim ainda pertencem ao INCRA, embora, já tenham sido doados (Oliveira, 2009).

Mesmo sem a licença ambiental para funcionamento da Praia da Amizade, a realização da festa "Itaquipesca" é liberada anualmente, pois a festa é autorizada diante de documentação específica enviada para o Instituto Brasileiro de Meio Ambiente (IBAMA), o Ministério da Pesca e a Polícia Ambiental, esclarece a gerente do Núcleo de Desenvolvimento Econômico e Turismo. Sobre a festa, ela acrescenta ainda que "essas atividades são permitidas pelo IBAMA porque ali é uma área de preservação sustentável que a gente pode fazer alguns tipos de atividades sem grandes impactos ambientais por isso que o IBAMA tem que aprovar". E complementa:

\begin{abstract}
$\mathrm{Na}$ verdade o que a gente queria da licença ambiental era pra construir uma infra-estrutura mais adequada pro turismo, é isso que a gente queria fazer lá. Agora do jeito que está a gente pode continuar tocando, claro que se o IBAMA chegar hoje ele vai embargar a Praia, é obvio, porque não tem licença pra funcionar. Agora o Itaquipesca é uma festa, então a Itaquipesca eles liberam. Eles não liberam o funcionamento da Praia, como balneário, um ponto turístico. Agora pra festa a gente consegue, e cumpre todas as determinações que eles passam que não é pouca coisa. As exigências são muito grandes. Ai vem a Polícia Ambiental que participa, a Marinha participa, fica o tempo todo fiscalizando, principalmente no dia da pesca (Oliveira, 2010).
\end{abstract}

Nas visitas ao local da festa no período de sua realização, é possível visualizar alguns problemas ambientais sérios que deveriam ser levados em consideração para tal atividade. A areia colocada na Praia da Amizade é proveniente do leito do rio Paraná, que se encontra em estado de assoreamento. Conseguimos diagnosticar isso através de visitas locais e imagens capturadas em diferentes épocas de trabalhos de campo. Empresas fazem a retirada de areia do rio Paraná em grandes quantidades com dragas.

Durante o período chuvoso o nível do rio Paraná sobe, o que acaba ocasionando destruição dos equipamentos de lazer da "prainha". Todos os anos, após a temporada de chuvas a prefeitura investe em reforma dos equipamentos que foram destruídos pelas águas, como churrasqueiras, pias de 
louça e áreas de lazer, como afirma a Oliveira durante entrevista concedida aos autores em abril de 2010.

Então em outubro, de qualquer forma, tendo ou não a Itaquipesca, tem que reformar tudo, pintar, por areia, deixar tudo "organizadinho" pra realização da (festa), para as pessoas que vêm aí final de ano, porque novembro, dezembro, já começa final de semana ferve a Praia, janeiro é uma coisa de louco.

Outro problema está relacionado ao assoreamento do rio Paraná nesse trecho, em períodos de cheia, quando é possível chegar, de barco, bem próximo a bancos de areia no leito do rio Paraná. Locais em que, devido ao intenso assoreamento, forma-se uma espécie de pastagem rala, onde muitos barqueiros levam os visitantes para jogar futebol e andar sobre esse banco de areia pelo rio Paraná.

Mesmo com o trabalho diário das dragas de remoção de areia do rio Paraná, a areia da "prainha" retorna para o rio, colaborando com o assoreamento, e carregando consigo destroços dos equipamentos lá instalados para atendimento as demandas de lazer.

O movimento de produção do lugar transformou a chamada prainha, fruto de atividades pretéritas de transporte no rio e apropriada para o lazer da população residente próxima deste trecho do rio Paraná, em atrativo turístico, a Praia da Amizade.

A produção do lugar turístico no assentamento rural está inserido no processo de produção do território turístico no meio rural, com a justificativa de geração de renda e fixação da família no campo. Mas como analisamos, as ações do poder público para a implantação da prática turística excluem os assentados da definição e dos benefícios da implantação da atividade. Resta aos assentados o trabalho precarizado e a perda de terras para as atividades relacionadas ao turismo.

\section{Considerações Finais}


Compreender a atividade turística no assentamento Sul Bonito e suas transformações no espaço rural resume a intenção do presente trabalho em entender como esta atividade interfere na produção e consumo do espaço, e na vida das famílias assentadas.

As transformações, como se pode verificar, vão além das transformações da paisagem. As mudanças se materializam no cotidiano das famílias, nas relações sociais e de trabalho. Entre os assentados e os turistas é produzido um novo território.

Essas mudanças determinam novos sentidos e significados, incorporando novos símbolos no espaço. As atividades urbanas se territorializam no rural através do modo de produção e (re) produção no espaço, consumindo, além da paisagem do assentamento, a o trabalho dos assentados.

A atividade turística é apenas uma das alternativas de produção inseridas no assentamento Sul Bonito e a que melhor representa a apropriação e consumo do espaço e da natureza, pois o espaço é natureza e o homem é natureza. Portanto, há o consumo do próprio homem na atividade turística, por isso é considerada um desafio para o desenvolvimento do assentamento, justamente porque ainda não oferece as condições favoráveis para tal, pois não incorpora os assentados nessa prática produtiva.

Identifica-se a necessidade de desenvolvimento da atividade turística no assentamento ao passo que esta atividade oferece condições para que os assentados, principais interessados, possam ser beneficiados com o turismo

\section{Referências}

BOSI, E. O que é desenraizamento? Revista de Cultura Vozes. Petrópolis, v.77, n.06, ano 77, 1983. In: MEDEIROS, R. M. V. Camponeses, cultura e inovações. En publicación: América Latina: cidade, campo e turismo. Amalia Inés Geraiges de Lemos, Mónica Arroyo, María Laura Silveira. CLACSO, Consejo Latinoamericano de Ciencias Sociales, San Pablo. Diciembre 2006.

CAMARATTA, E. B. El turismo como práctica social y su papel en la apropiación y consolidación del territorio. En publicación: América Latina: cidade, campo e turismo. Amalia Inés Geraiges de Lemos, Mónica Arroyo, María Laura Silveira. 
CLACSO, Consejo Latinoamericano de Ciencias Sociales, San Pablo. Diciembre 2006.

CORIOLANO, L. N. M. T. Turismo: prática social de apropriação e de dominação de territórios. En publicación: América Latina: cidade, campo e turismo. Amalia Inés Geraiges de Lemos, Mónica Arroyo, María Laura Silveira. CLACSO, Consejo Latinoamericano de Ciencias Sociales, San Pablo. Diciembre, 2006.

CRUZ, R. C. A. Política de turismo e território. São Paulo: Contexto, 2000. (Coleção Turismo).

LUCATO MORETTI, S. A. Atividade turística e transformações territoriais no município de Jardim - MS. Dourados/ MS: UFMS, 2002, Dissertação.

OCON, D. C. M. Espaço geográfico: reprodução e consumo através da atividade turística em Anaurilândia e Fátima do Sul - MS - Brasil. Dourados/ MS: UFGD, 2009. Dissertação.

RODRIGUES, A. M. O mito da sustentabilidade da atividade turística. In: BANDUCCI JÚNIOR, A.; MORETTI, E. C. (Orgs.) Qual Paraíso? Turismo e ambiente em Bonito e no Pantanal. São Paulo: Chronos: Campo Grande: UFMS, 2001.

RODRIGUES, A. M. Desenvolvimento sustentável e atividade turística, In: LUCHIARI, M. T. D. P. (Org.). Turismo e meio ambiente. Coleção Textos Didáticos. Campinas: IFCH/UNICAMP, no 31(2), 1997.

SCHNEIDER, M. M. M. O Parque Nacional de Ilha Grande, produção e consumo do território turístico. Dourados/ MS: UFGD, 2009. Dissertação.

WANDERLEY, M. N. B. O mundo rural como um espaço de vida: reflexões sobre a propriedade da terra, agricultura familiar e ruralidade. Porto Alegre: UFRGS, 2009. 